\title{
CORRELATION OF GENDER AND LEPTIN WITH ANALGESIC EFFECT OF TRAMADOL IN RATS
}

\author{
SHAKTA MANI SATYAM ${ }^{1 *}$, LAXMINARAYANA KURADY BAIRY², VASUDHA DEVI ${ }^{1}$
}

${ }^{1}$ Department of Pharmacology, Melaka Manipal Medical College, Manipal Campus, Manipal Academy of Higher Education, Manipal - 576 104, Karnataka, India. ${ }^{2}$ Department of Pharmacology, RAK College of Medical Sciences, RAK Medical and Health Sciences University, UAE. Email: smsatyam21@gmail.com

Received: 13 April 2018, Revised and Accepted: 05 May 2018

ABSTRACT

Objective: The objective of the study was to investigate the correlation of gender and serum leptin level with analgesic modulation of tramadol in Wistar rats.

Methods: A total of 48 Wistar rats (body weight 100-150 g), 24 each male and female Wistar rats were randomly divided into two groups (n=6/group) (Group I - Control- 0.9\% NaCl; $1 \mathrm{ml} / \mathrm{kg} /$ day i.p. and Group II - Tramadol $10 \mathrm{mg} / \mathrm{kg} /$ day i.p.) for each nociception model - plantar test and acetic acid induced writhing test. The treatment duration was of 5 days. Paw withdrawal latency (PWL) was assessed using plantar test and writhing movements were observed following administration of $0.8 \%$ acetic acid; $10 \mathrm{ml} / \mathrm{kg}$ i.p.

Results: PWL was significantly decreased $(\mathrm{p}<0.001)$ and both number of writhing movements and serum leptin concentrations were significantly increased $(\mathrm{p}<0.001)$ in female control group compared to male control group. In tramadol treated female rats, PWL was significantly decreased $(\mathrm{p}=0.005)$ and both number of writhing movements and serum leptin concentrations were significantly increased $(\mathrm{p}<0.001)$ in comparison with the tramadol treated male rats. PWL was negatively correlated with serum leptin concentration (Pearson correlation coefficient $=-0.826$, two-tailed significance $=0.000)$, and writhing movements were positively correlated with serum leptin concentration (Pearson correlation coefficient= 0.505 , two-tailed significance $=0.012$ ).

Conclusions: The present study revealed that female rats have more serum leptin concentration than male rats which could be one of the possible reasons for having more pain sensitivity to noxious stimuli in female rats compared to male rats. Tramadol treatment at the dose of 10 mg/kg for 5 days has decreased serum leptin level in rats which might be one of the additional mechanisms of tramadol to reduce pain.

Keywords: Pain threshold, Sex hormone, Leptin, Opioids, Obesity, Writhing, Plantar, Acetic acid.

(C) 2018 The Authors. Published by Innovare Academic Sciences Pvt Ltd. This is an open access article under the CC BY license (http://creativecommons. org/licenses/by/4. 0/) DOI: http://dx.doi.org/10.22159/ajpcr.2018.v11i6.26678

\section{INTRODUCTION}

In pathological term, pain may be defined as "sensory consequence of neuronal activity triggered by noxious stimuli, inflammation or damage to specific nociceptive pathways in the nervous system [1]. It is quite evident for any clinician who treats patients in pain knows that one size does not fit all. There is no one standard dose or specific medication that will provide adequate analgesia to all patients. The optimal current approach is to titrate analgesics to produce optimal therapeutic benefit.

Gender-related influences on the experience of pain have been received considerable empirical attention in recent years [2-7]. It is generally accepted that males and females respond differently to painful conditions. Women report more pain than men and are at greater risk for developing many forms of chronic pain [2]. Sex differences are not limited to pain perception but may extend to the response to analgesics. There is little agreement about a differential response of men and women to opioid analgesics. In animals, male rats exhibit greater analgesia than female rats to equal doses of opioids [8,9]. In case of morphine, a gender difference is reported in its anti-nociceptive effect both in animals and human in spite of no gender-linked difference in serum levels of morphine [10-12]. In humans, sex differences in response to opioids have been described, but the findings are difficult to consolidate.

Leptin is secreted by adipocytes in proportion to the amount of body fat and exerts a potent inhibitory action on food intake. In humans, serum leptin concentrations correlate positively with percent body fat. Several studies have positively correlated the experience of pain with an increase in body mass index (BMI) $[13,14]$. It is not known whether obesity causes chronic pain, chronic pain causes obesity, or some other factor causes both concurrently. Obesity is hypothesized to lead to pain because of excess mechanical stresses and its pro-inflammatory state.

Differences in pain thresholds may have implications for pain management, as they may account in part for the variability in analgesic requirements between individuals. There is a need for further studies to investigate the correlation of gender and leptin with pain threshold and analgesic effect of opioids. Tramadol is a synthetic, centrally acting analgesic agent with two distinct, synergistic mechanisms of action, acting as both a weak opioid agonist and an inhibitor of monoamine neurotransmitter reuptake [15]. Earlier, we had reported the analgesic modulation of some analgesics in male and female Wistar rats [16]. Consequently, the aim of the present study was to investigate the correlation of gender and leptin with analgesic effect of tramadol in Wistar rats.

\section{METHODS}

\section{Drugs and reagents}

Active pharmaceutical ingredient of tramadol and rat leptin ELISA kit was procured from Sigma-Aldrich, Bengaluru, India. Acetic acid and other chemicals were purchased from Merck Life Sciences Pvt., Ltd., Mumbai, India. Normal saline $(0.9 \%$ sodium chloride) was purchased from the pharmacy of Kasturba Hospital, Manipal, Karnataka, India.

\section{Animals}

A total of 48 (24 male and 24 female) Wistar rats weighing 100-150 g were housed in separate polypropylene cages, maintained under standard conditions with temperature $\left(22-24^{\circ} \mathrm{C}\right), 12-\mathrm{h}$ light/12-h dark cycle and relative air humidity $40-60 \%$. The animals were 


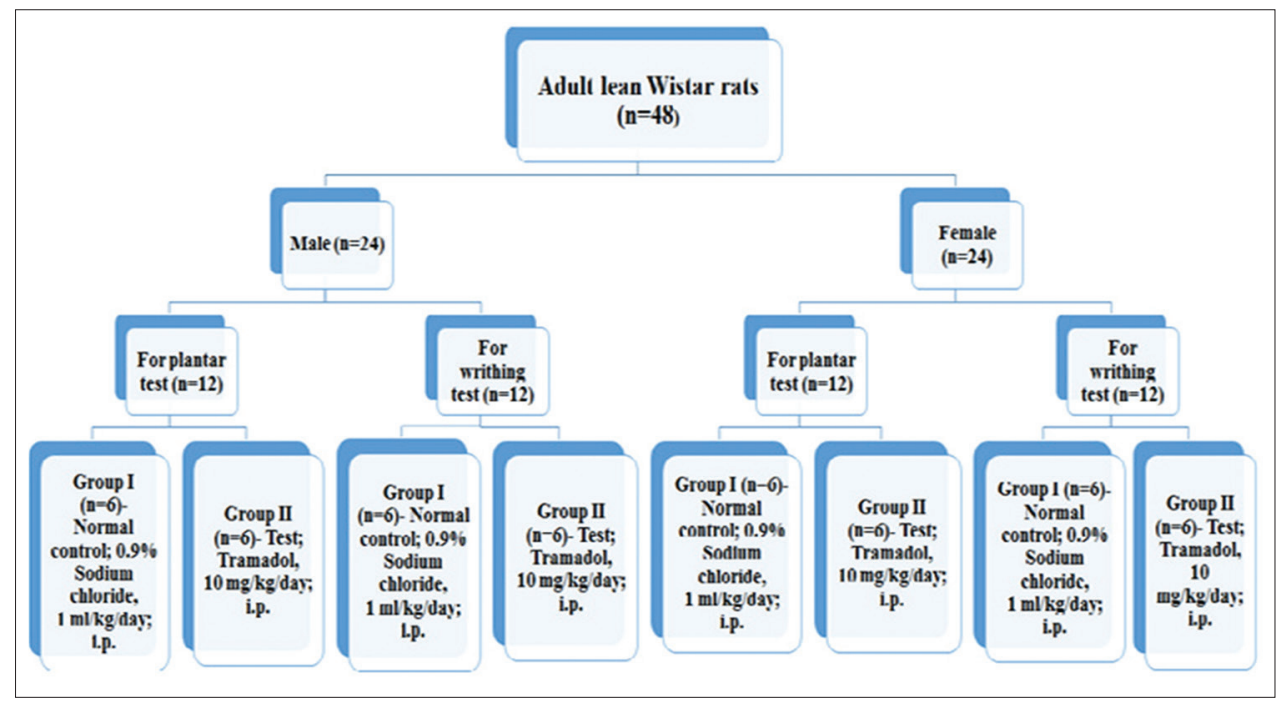

Fig. 1: Experimental design

acclimatized to the laboratory conditions for 1 week before the start of the experiment. The animals were provided with a normal pellet diet (Amrit Feeds Ltd., Pune, India) and water ad libitum. The experimental protocol was approved by the Institutional Animal Ethics Committee (IAEC/KMC/41/2014) and experiments were conducted according to the ethical norms approved by the Ministry of Social Justice and Empowerment, Government of India, and Committee for the Purpose of Control and Supervision of Experiments on Animals guidelines.

\section{Experimental design}

A total of 48 Wistar rats (body weight 100-150 g), 24 each male and female Wistar rats were randomly divided into two groups ( $\mathrm{n}=6 /$ group) (Group I - Control- 0.9\% NaCl; 1 ml/kg/day i.p. and Group II - Tramadol $10 \mathrm{mg} / \mathrm{kg} /$ day i.p.) for each nociception model - plantar test and acetic acid induced writhing test (Fig. 1). The treatment duration was of 5 days. On the last day of treatment (i.e. on the $5^{\text {th }}$ day); 15 min after tramadol/ normal saline treatment, animals were tested for the respective pain model. Paw withdrawal latency (PWL) was assessed using plantar test, and writhing movements were observed following administration of $0.8 \%$ acetic acid; $10 \mathrm{ml} / \mathrm{kg}$ i.p [16-18].

\section{Nociception models}

\section{Plantar test (Hargreaves' method)}

Thermal pain threshold to radiant heat (IR-90) was quantified using the paw withdrawal test (Fig. 2). Rats were placed in a perspex enclosure, without restraint and a movable infrared radiant heat source placed directly under the plantar surface of the hind paw (Ugo Basile, Como, Italy). The PWL to radiant heat was defined as the time from onset of the radiant heat to the withdrawal of the rat hind paw. The cutoff time for PWL was $30 \mathrm{~s}$. Testing was alternated between hind paws and carried out at $3 \mathrm{~min}$ intervals. The average of three estimations was taken to yield mean PWL. Before any testing was carried out, rats could adjust to their environments for at least $10 \mathrm{~min}$.

\section{Acetic acid-induced writhing test}

Writhing movement was induced by administering an intraperitoneal injection of $0.8 \%$ acetic acid $(10 \mathrm{ml} / \mathrm{kg}), 15 \mathrm{~min}$ after the tramadol/ normal saline administration. After $10 \mathrm{~min}$ of acetic acid administration, the number of writhing movements such as abdominal constriction/ elongation of body/arching of back/hind limb extension/forelimb extension/trunk twisting (Fig. 3) was cumulatively counted over 20 min further for nociceptive evaluation [16-18].

\section{Collection of blood sample}

Following anesthesia with ketamine $60 \mathrm{mg} / \mathrm{kg}$ and xylazine $5 \mathrm{mg} / \mathrm{kg}$; i.p., blood was withdrawn from retro-orbital plexus of rats through
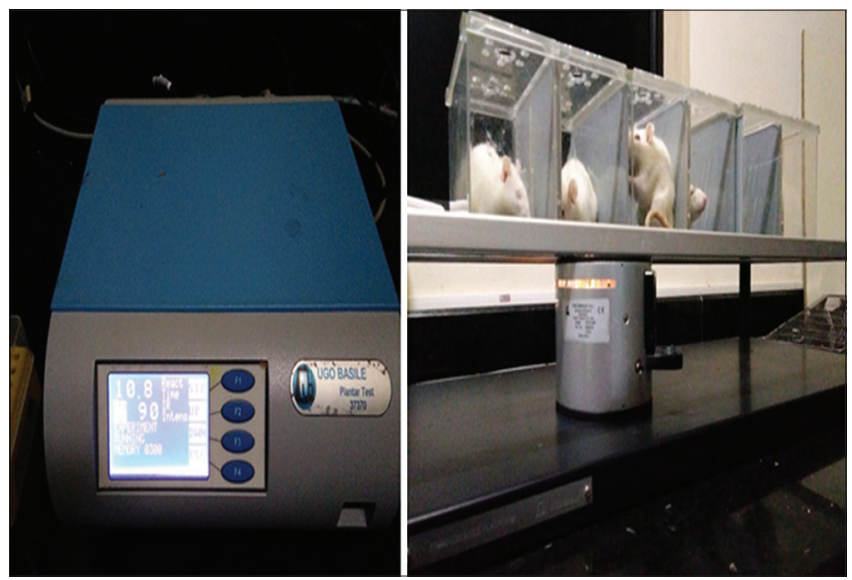

Fig. 2: Hargreaves apparatus for plantar test
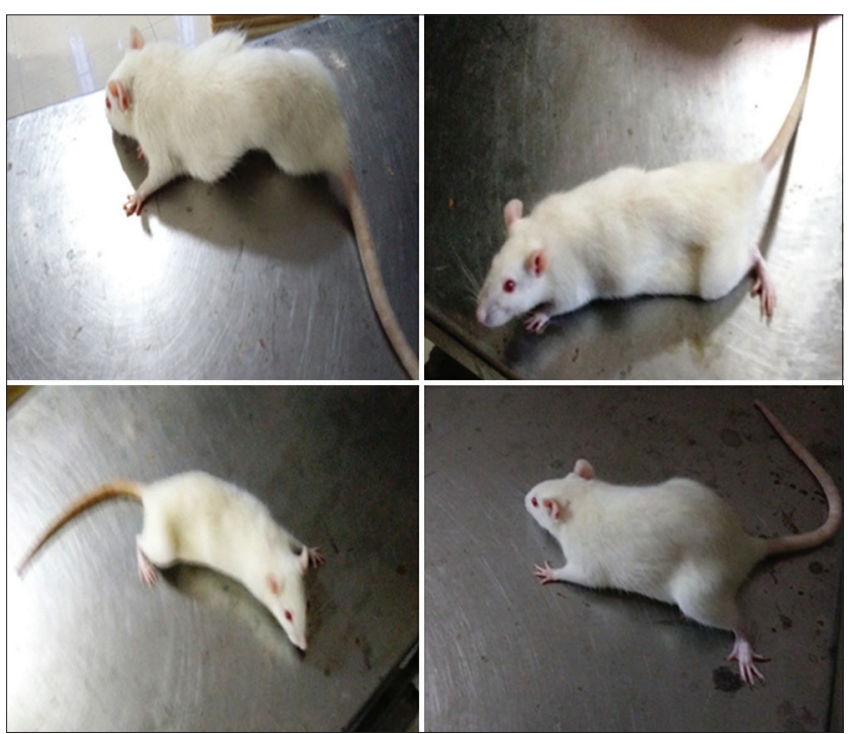

Fig. 3: (a-d) Acetic acid-induced writhing movements

capillary tube [19]. Following collection of blood in micro-centrifuge tubes and its clot formation, serum was obtained by centrifugation of blood at 3,000 rpm for $20 \mathrm{~min}$ at $4^{\circ} \mathrm{C}$ using a refrigerated centrifuge (MIKRO 22R, Andreas Hettich GmbH \& Co. KG, Germany). The 
resulting supernatant (serum) was stored at $-80^{\circ} \mathrm{C}$ for estimation of leptin concentration. All the surviving experimental animals were rehabilitated after the completion of the study.

\section{Estimation of serum leptin concentration}

As per the assay protocol given along with rat leptin ELISA kit, all reagents and samples were kept at room temperature $\left(22-25^{\circ} \mathrm{C}\right)$ before use. $100 \mu \mathrm{l}$ of each standard and sample was added to appropriate wells. Wells were covered and incubated for $2.5 \mathrm{~h}$ at room temperature or overnight at $4^{\circ} \mathrm{C}$ with gentle shaking. The solution was discarded and washed 4 times with $1 \mathrm{x}$ wash solution. Washing by filling each well with wash buffer $(300 \mu \mathrm{l})$ was done using a multichannel pipette. After the last wash, any remaining wash buffer was removed by aspirating or decanting. The plate was inverted and blotted against clean paper towels. $100 \mu \mathrm{l}$ of $1 \mathrm{x}$ prepared Biotinylated Detection Antibody was added to each well followed by incubation for $1 \mathrm{~h}$ at room temperature with gentle shaking. The solution was discarded. Washing was repeated 4 times. $100 \mu \mathrm{l}$ of prepared HRP-streptavidin solution was added to each well followed by incubation for $45 \mathrm{~min}$ at room temperature with gentle shaking. Solution was discarded and washed again 4 times. $100 \mu \mathrm{l}$ of ELISA Colorimetric TMB Reagent was added to each well followed by incubation for $30 \mathrm{~min}$ at room temperature in the dark with gentle shaking. $50 \mu \mathrm{l}$ of stop solution was added to each well and absorbance was read at $420 \mathrm{~nm}$ immediately. The mean absorbance for each set of duplicate standards, controls, and samples was entered in the Microsoft Excel sheet, and average zero standard optical density was subtracted from each mean absorbance. A standard curve with standard concentration on the X-axis and absorbance on the Y-axis was plotted and following that leptin concentration $(\mathrm{pg} / \mathrm{ml})$ was calculated.

\section{Statistical analysis}

Using Statistical Package for the Social Sciences version 16.0, data were expressed as mean \pm standard deviation and analyzed by one-way analysis of variance followed by post hoc Tukey test. The correlation of pain and serum leptin concentration was done using bivariate analysis followed by Pearson correlation coefficient and two-tailed significance. A level for $\mathrm{p} \leq 0.05$ was considered as statistically significant.

\section{RESULTS}

PWL was significantly decreased $(\mathrm{p}<0.001)$ and both number of writhing movements and serum leptin concentrations were significantly increased $(p<0.001)$ in female control group compared to male control group. Tramadol treated both male and female rats had significantly increased PWL $(p<0.001)$ and decreased both number of writhing movements and serum leptin concentration $(\mathrm{p}<0.001)$ in comparison with both male and female control groups, respectively. In tramadol treated female rats, PWL was significantly decreased $(\mathrm{p}=0.005)$ and both number of writhing movements and serum leptin concentration were significantly increased $(p<0.001)$ in comparison with the tramadol treated male rats (Fig. 4). PWL was negatively correlated with serum leptin concentration (Pearson correlation coefficient $=-0.826$ and two-tailed significance $=0.000$ ), which means PWL was significantly decreasing (means more pain) with increased levels of serum leptin (Fig. 5). A number of writhing movements were positively correlated with serum leptin concentration (Pearson correlation coefficient $=0.505$ and two-tailed significance $=0.012$ ), which means writhing movements were significantly increasing (means more pain) with increased levels of serum leptin levels (Fig. 6).

\section{DISCUSSION}

The present study has demonstrated the correlation of gender and leptin with analgesic modulation of tramadol in Wistar rats. We found the significant increase in serum leptin levels and decrease in pain threshold (more pain sensitivity to noxious stimuli) in female rats than male rats. The significant increase in serum leptin concentration in female rats in the present study is in agreement with Mendonca et al. who found a positive and statistically significant correlation between estrogen and leptin independent of body mass index [20]. According to Shimizu et al. and Messinis et al., estrogen can be an important regulator of leptin production in women $[21,22]$. The gender difference in serum leptin concentration is well established and in vitro results suggest that gonadal hormones, such as testosterone, may be important regulators of leptin secretion [23-25]. In both humans and rodents, males have lower plasma leptin concentrations than their female counterparts at any level of adiposity [26,27]. A strong inverse association between serum levels of leptin and testosterone was recently reported in untreated and testosterone-treated hypogonadal men $[28,29]$. In the present study also, we found significantly lower levels of leptin in male rats compared to female rats which might be due to downregulation of serum leptin by testosterone. The mechanism underlying this effect of testosterone remains to be elucidated.

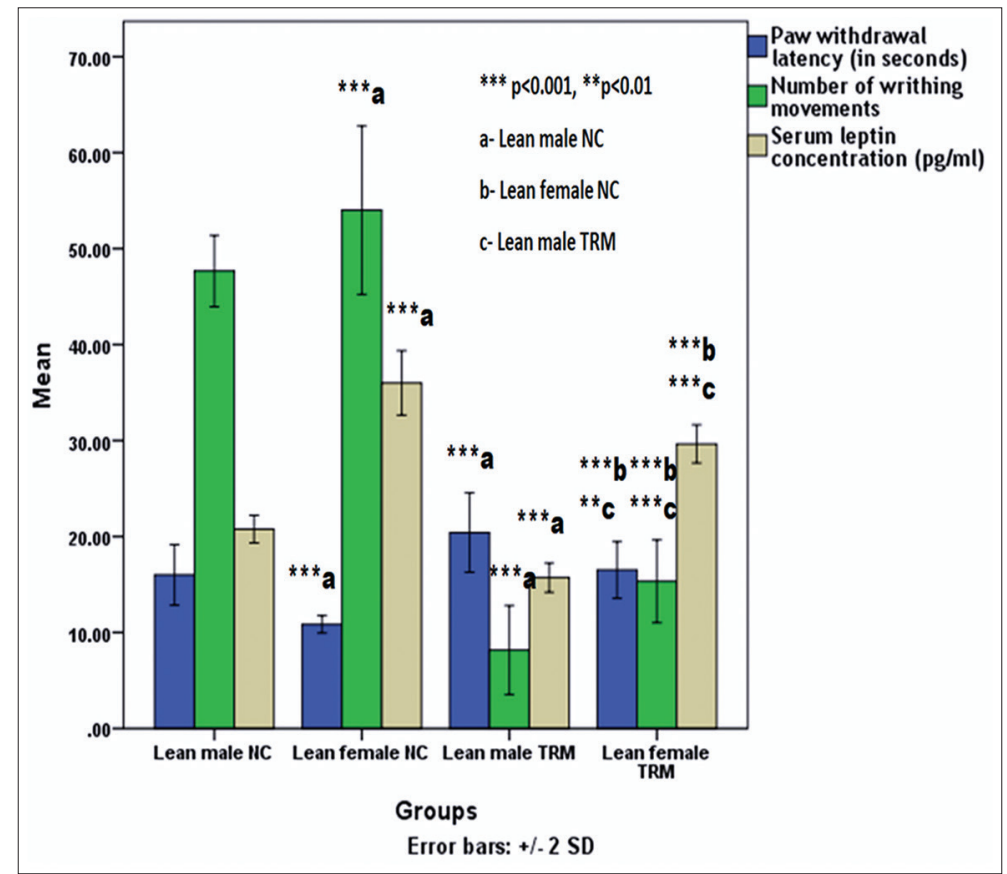

Fig. 4: Comparison of paw withdrawal latency (in seconds), number of writhing movements, and serum leptin concentration (pg/ml) among experimental groups 


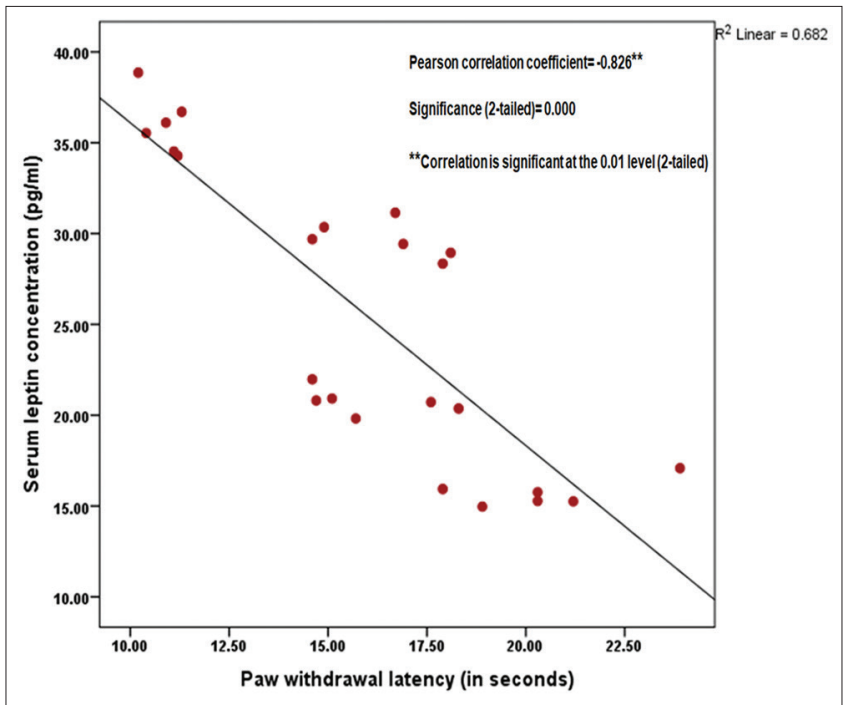

Fig. 5: Correlation between paw withdrawal latency (in seconds) and serum leptin concentration $(\mathrm{pg} / \mathrm{ml})$

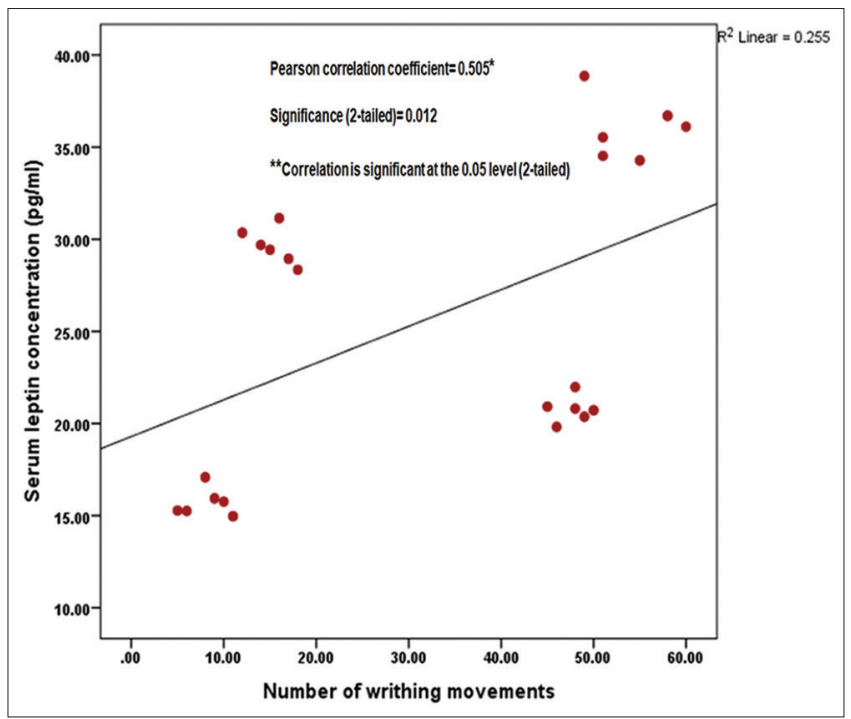

Fig. 6: Correlation between number of writhing movements and serum leptin concentration $(\mathrm{pg} / \mathrm{ml})$

In the present study, tramadol treatment at the dose of $10 \mathrm{mg} / \mathrm{kg}$ for 5 days has decreased serum leptin level in both male and female rats. Some of the studies also suggest the decrease in serum leptin concentration with tramadol (opioid agonist) treatment at the dose of $0.5 \mathrm{mg} / \mathrm{kg} /$ day orally when administered for 4 weeks [30,31]. If we calculate the total amount of tramadol for 5 days in our study which comes to $50 \mathrm{mg} / \mathrm{kg}$ and in the above-mentioned studies it is $14 \mathrm{mg} / \mathrm{kg}$ in the total 4 weeks duration then the dose and duration of tramadol treatment in our study is even more than these studies where serum leptin level was decreased. Decrease in serum leptin level by tramadol at the dose of $10 \mathrm{mg} / \mathrm{kg}$ for 5 days treatment duration could be one of the additional mechanisms of tramadol to reduce pain.

There was a significant positive correlation found between pain and serum leptin levels in our study. One of the effects of increased serum leptin levels may be greater sensitivity to pain. The relationship between leptin and pain may be modulated by other factors, with estrogen being one possibility [32]. In rat and mouse models, leptin has been shown to reduce the threshold for pain [33]. Leptin has also been shown to increase levels of interleukin-1, a cytokine known to cause hyperalgesia [34]. Recent studies have shown that leptin, an adipocytokine, played a significant role in nociceptive behavior induced by nerve injury in rats $[35,36]$. Maeda et al. suggests that peripheral effect of leptin on neuropathic pain is mediated via macrophage stimulation [36]. Following more leptin levels in female rats compared to males, these could be the possible reasons for more pain in female rats than male rats.

\section{CONCLUSIONS}

The present study revealed that female rats have more serum leptin concentration than male rats which could be one of the possible reasons for having more pain sensitivity to noxious stimuli in female rats compared to male rats. Further information regarding the link between leptin and pain may help drive novel treatments for pain. Tramadol treatment at the dose of $10 \mathrm{mg} / \mathrm{kg}$ for 5 days has decreased serum leptin level in rats which might be one of the additional mechanisms of tramadol to reduce pain. Additional research to elucidate the mechanisms driving sex hormones and leptin in pain responses is needed to foster future interventions to reduce these disparities in pain and analgesic modulation of tramadol. Gender and body mass index-specific tailoring of pain treatments may become a conceivable outcome in the foreseeable future.

\section{ACKNOWLEDGMENT}

The authors are grateful to Manipal Academy of Higher Education, Manipal, Karnataka, India, for their support toward the accomplishment of this work.

\section{AUTHOR'S CONTRIBUTION}

The first author has designed the study, carried out the experimental part of the research study, data compilation, statistical analysis, interpretation of results, and manuscript writing. The second author has guided the first author and monitored the experiment, statistical analysis, interpretation of result. The third author has coguided the first author.

\section{CONFLICTS OF INTEREST}

All the authors declare that they do not have any conflicts of interest.

\section{REFERENCES}

1. Scholz J, Woolf CJ. The neuropathic pain triad: Neurons, immune cells and glia. Nat Neurosci 2007;10:1361-8.

2. Fillingim RB. Sex differences in analgesic responses: Evidence from experimental models. Eur J Anaesthesiol 2002;19 Suppl. 26:16-24.

3. Isacson D, Bingefors K. Epidemiology of analgesic use: A gender perspective. Eur J Anaesthesiol 2002;19 Suppl. 26:5-15.

4. Starowicza K, Cocka BP. The role of melanocortins and their receptors in inflammatory processes, nerve regeneration and nociception. J Life Sci 2003;73:823-47.

5. Priyanka V, Rekha V. Analgesic, anti-inflammatory and antipyretic activity of Cissus quadrangularis. J Pharm Sci Technol 2010;2:111-8.

6. Maria TC, Cenzo C, Valentina O, Micaela M, Omar C. Synthesis of ibuprofen heterocyclic amides and investigation of their analgesic and toxicological properties. Euro J Med Chem 2003;38:513-8.

7. Biçer F, Eti Z, Aricioglu F, Konya D, Gogus Y. The effects of gabapentin, tramadol and amitriptyline on pain behavior in a rat neuropathic pain model: 14AP10-2. Euro J Anaesthesiol 2010;27:217.

8. Kepler KL, Standifer KM, Paul D, Kest B, Pasternak GW, Bodnar RJ. Gender effects and central opioid analgesia. Pain 1991;45:87-94.

9. Cicero TJ, Nock B, Meyer ER. Sex-related differences in morphine's antinociceptive activity: Relationship to serum and brain morphine concentrations. J Pharmacol Exp Ther 1997;282:939-44.

10. Fillingim RB, Ness TJ, Glover TL, Campbell CM, Hastie BA, Price DD, et al. Morphine responses and experimental pain: Sex differences in side effects and cardiovascular responses but not analgesia. J Pain 2005;6:116-24.

11. Cicero TJ, Nock B, Meyer ER. Gender-related differences in the anti-nociceptive properties of morphine. J Pharmacol Exp Ther 1996;279:767-73.

12. Kest B, Palmese C, Hopkins E. A comparison of morphine analgesic tolerance in male and female mice. Brain Res 2000;879:17-22. 
13. Finkelstein EA, Fiebelkorn IC, Wang G. State-level estimates of annual medical expenditures attributable to obesity. Obesity Res 2004;12:18-24.

14. World Health Organization. Obesity: Preventing and Managing the Global Epidemic. Geneva (Switzerland): World Health Organization; 1997.

15. Sirisha G, Rahul PB, Usha NS, Madhu DK. Evaluation of antidepressant effect of chronic administration of tramadol alone and in combination with fluoxetine in low doses in albino mice. Int J Pharm Pharm Sci 2014;6:101-5

16. Chogtu B, Bairy KL, Satyam SM, Pirasanthan R, Gupta S. Analgesic modulation of tramadol, amitriptyline and gabapentin in male and female wistar rats. Res J Pharm Biol Chem Sci 2013;4:70-8.

17. Motaghinejad M, Ebrahimzadeh A, Shabab B. Preventive effect of central administration of venlafaxine on morphine physical dependence, nociception, and blood cortisol level in rat. Int J Prev Med 2014:5:1422-31.

18. Prabhu VV, Nalini G, Chidambaranathann N, Kisan SS. Evaluation of anti-inflammatory and analgesic activity of Tridax procumbens linn against formalin, acetic acid and CFA induced pain models. Int J Pharm Pharm Sci 2011;3:126-30.

19. Selim K, Sinan C, Suleyman S, Mete O, Mustafa S, Haluk K. Effects of central and peripheral administration of leptin on pain threshold in rats and mice. Neuroendocrinol Lett 2003;24:193-6.

20. Mendonca HC, Montenegro RM, Foss MC, Silva de Sa MF, Ferriani RA. Positive correlation of serum leptin with estradiol levels in patients with polycystic ovary syndrome. Braz J Med Biol Res 2004;37:729-36.

21. Shimizu H, Shimomura Y, Nakanishi Y, Futawatari T, Ohtani K, Sato N, Mori M. Estrogen increases in vivo leptin production in rats and human subjects. J Endocrinol 1997;154:285-92.

22. Messinis IE, Milingos S, Zikopoulos K, Kollios G, Seferiadis K, Lolis D. Leptin concentrations in the follicular phase of spontaneous cycles and cycles superovulated with follicle stimulating hormone. Hum Reprod 1998;13:1152-6.

23. Rosenbaum M, Nicolson M, Hirsch J, Heymsfield SB, Gallagher DY, Chu FL, et al. Effects of gender, body composition, and menopause on plasma concentrations of leptin. J Clin Endocrinol Metab 1996;81:3424-7.

24. Hickey MS, Israel RG, Gardiner SN, Considine RV, McCammon MR, Tyndall GL, et al. Gender differences in serum leptin levels in humans. Biochem Mol Med 1996;59:1-6.

25. Kennedy A, Gettys TW, Watson P, Wallace P, Ganaway E, Pan QI, et al. The metabolic significance of leptin in humans: Gender-based differences in relationship to adiposity, insulin sensitivity, and energy expenditure. J Clin Endocrinol Metab 1997;82:1293-300.

26. Frederich RC, Hamann A, Anderson S, Lollmann B, Lowell BB, Flier JS. Leptin levels reflect body lipid content in mice: Evidence for diet-induced resistance to leptin action. Nat Med 1995;1:1311-4.

27. Saad MF, Damani S, Gingerich RL, Riad-Gabriel MG, Khan A., Boyadjian R, et al. Sexual dimorphism in plasma leptin concentration. J Clin Endocrinol Metab 1997:82:579-84.

28. Bhasin S, Storer TW, Berman N, Yarasheski KE, Clevenger B, Phillips J, et al. Testosterone replacement increases fat-free mass and muscle size in hypogonadal men. J Clin Endocrinol Metab 1997;82:407-13.

29. Behre HM, Simoni M, Nieschlag E. Strong association between serum levels of leptin and testosterone in men. Clin Endocrinol (Oxf) 1997; 47:237-40.

30. Ibrahim IY, Ibrahim HM, Aziz NM, Rahman DM. Effect of opioid receptors modulation on the HFD-Induced obesity in adult male Albino rats. Malays J Med Res 2014;25:72-81.

31. Anghel A, Jamieson C, Ren X, Young J, Porche R, Ozigbo E, et al. Gene expression profiling following short-term and long-term morphine exposure in mice uncovers genes involved in food intake. Neurosci 2010;167:554-66.

32. Alvarez P, Bogen O, Chen X, Giudice LC, Levine JD. Ectopic endometrium-derived leptin produces estrogen dependent chronic pain in a rat model of endometriosis. Neuroscience 2014;258:111-20.

33. Kutlu S, Canpolat S, Sandal S, Ozcan M, Sarsilmaz M, Kelestimur H. Effects of central and peripheral administration of leptin on pain threshold in rats and mice. Neuro Endocrinol Lett 2003;24:193-6.

34. Hosoi T, Okuma Y, Nomura Y. Leptin regulates interleukin-1beta expression in the brain via the STAT3-independent mechanisms. Brain Res Mol Brain Res 2002;13:139-46.

35. Lim G, Wang S, Zhang Y, Tian Y, Mao J. Spinal leptin contributes to the pathogenesis of neuropathic pain in rodents. J Clin Invest 2009; 119:295-304

36. Maeda T, Kiguchi N, Kobayashi Y, Ikuta T, Ozaki M, Kishioka S. Leptin derived from adipocytes in injured peripheral nerves facilitates development of neuropathic pain via macrophage stimulation. Proc Natl Acad Sci USA 2009;106:13076-81. 